\title{
Where next for youth mental health services in Ireland?
}

\author{
J. McMahon ${ }^{1,2, *}$, F. Ryan ${ }^{1,3}$, M. Cannon ${ }^{1,4}$, G. O'Brien ${ }^{1,5}$, M. O'Callaghan ${ }^{1,6}$, R. Flanagan ${ }^{1,7}$, K. O'Connor ${ }^{1,8}$, \\ D. Chambers ${ }^{1,3}$, S. Byrne ${ }^{1,9}$ and P. McGorry ${ }^{10,11}$ \\ ${ }^{1}$ Association of Child \& Adolescent Mental Health (ACAMH), Irish Special Interest Group in Youth Mental Health \\ ${ }^{2}$ Teaching for Inclusion Research Lab (i-TEACH), School of Education, University of Limerick, Limerick, Ireland \\ ${ }^{3}$ ReachOut Ireland, 32 South William Street, Dublin 2, Ireland \\ ${ }^{4}$ Jigsaw, The National Centre for Youth Mental health, Dublin, Ireland \\ ${ }^{5}$ Department of Psychiatry, Royal College of Surgeons in Ireland, Dublin, Ireland \\ ${ }^{6}$ St. Patrick's University Hospital, James St., Dublin, Ireland \\ ${ }^{7}$ GLEN - the LGBTI equality network, 2 Exchange Street Upper, Dublin 8, Ireland \\ ${ }^{8}$ Department of Psychiatry, Health Service Executive, Ireland \\ ${ }^{9}$ School of Psychology, Trinity College Dublin, Ireland \\ 10 ORYGEN Research Centre, Parkville, VIC, Australia \\ ${ }^{11}$ Department of Psychiatry, University of Melbourne, Melbourne, VIC, Australia
}

To date, Ireland has been a leading light in the provision of youth mental health services. However, cognisant of the efforts of governmental and non-governmental agencies working in youth mental health, there is much to be done. Barriers into care as well as discontinuity of care across the spectrum of services remain key challenges. This editorial provides guidance for the next stage of development in youth mental care and support that will require significant national engagement and resource investment.

Received 16 June 2017; Revised 27 March 2018; Accepted 28 March 2018; First published online 1 June 2018

Key words: Adolescence, evidence based, intervention, mental health services, service delivery, youth mental health.

\section{Editorial}

Heightened concern for the health and well-being of young people (Patton et al. 2016; Bo, 2017) has given rise to an international youth mental health movement, with focus on the provision of youth mental health services (Malla et al. 2016). Together with Australia, Canada and the United Kingdom, Ireland has been at the forefront of this movement (McGorry et al. 2013). Yet despite considerable progress, the transformation of the Irish youth mental health landscape still has a long way to go.

Youth, defined here as 12-25-year olds, is a period of biological, psychological and social changes (Birchwood \& Singh, 2013), which can create challenges for young people as they navigate to adulthood. The complexities of these challenges result in many young people requiring mental health support. Internationally, the peak period for the onset of mental health problems has been identified as adolescence and early adulthood (Kessler et al. 2005, 2007) and it is estimated that one in five young people is experiencing a diagnosable mental

\footnotetext{
* Address for correspondence: J. McMahon, i-Teach Lab, School of Education, Faculty of Education \& Health Sciences, University of Limerick, Limerick, Ireland.

(Email: jennifer.mcmahon@ul.ie)
}

disorder at any given time (Costello et al. 2011). Within Ireland, lifetime prevalence for any Axis I DSM-IV disorder of $38.8 \%$ has been found among 11-13-year olds (Coughlan et al. 2014) and of 56\% among 19-24-year olds (Cannon et al. 2013) has been found.

Additional challenges arise when support for mental health issues is sought. The traditional model of mental health services, which is divided into child and adolescent services and adult services, sees a transition for young people once they turn 18 years old. In the Irish context, an analysis of the youth mental health sector suggests that, despite advances, a coherent continuum of services and supports is still lacking (O'Reilly et al. 2015; Malla et al. 2016). Examples of good practice do exist. For example, Jigsaw, a primary care youth mental health service in Ireland provides accessible, responsive community-based supports for young people experiencing mild-to-moderate mental health difficulties. Since its inception over 10500 Irish youth has availed of the service and evidence of effectiveness is emerging (O'Reilly et al. 2015). The 13 Jigsaw services are almost exclusively publicly funded underlining the commitment of successive governments and the Health Service Executive (HSE) in Ireland to youth mental health. However, this much-needed service is still only available in nine of 26 counties. More broadly, the 
resourcing and delivery of mental health services across primary, secondary and tertiary care are variable. Barriers into care as well as discontinuity of care across the spectrum of services still endure. This can lead to unmet and poorly managed need, which in mental health care, is particularly problematic given that untreated, or poorly treated mental health problems are associated with poorer outcomes (Kohn et al. 2004; Dell'Osso et al. 2013; Burns \& Birrell, 2014).

The International Declaration on Youth Mental Health (IAYMH, 2011) set out a shared global vision, principles and action plan for mental health service provision for young people aged 12-25 years with countries such as Australia providing exemplars of transformational change across both primary and specialist care levels (McGorry et al. 2013). Enacting the IAYMH plan in Ireland will 'necessitate a commitment among leaders and professionals within the field, to challenge traditional service delivery models and to consider how best to use available resources to better meet young people's mental health needs' (Coughlan, 2013). Undoubtedly, the challenges to professionals, researchers and policymakers in the field of youth mental health are considerable and beg the question, where do we go from here?

Drawing from international best practice and documents such as the IAYMH (2011) we propose evidencebased direction for the redesign of services in Ireland if we are to continue to lead the way in youth mental health care and provision.

\section{Take a human rights-based approach to mental health}

The United Nations Resolution on Mental Health (United Nation General Assembly, 2010) calls for a human rightsbased approach to mental health. Such an approach emphasises mental health as an integral part of the right to good health, on par with physical health, and provides for the right of both children and adults to access timely and appropriate mental health supports and services. Ireland continues to be out of step with international best practice in this regard and has been negatively evaluated for shortcomings in implementing the government mental health policy A Vision for Change (Mental Health Reform, 2015). For example, Ireland has seen an increase in the number of children and adolescents to adult mental health units. In the first 5 months of 2017, there were 44 child admissions to adult units compared to 36 for the same period in 2016 (Mental Health Commission, 2017). This is an unacceptable feature of mental health practice in Ireland. A human rights approach would not only provide for dignity and respect in accessing mental health support but also allow for accountability and redress when failings or shortcomings of this nature occur.
Youth participation is also a critical component of a human rights approach and helps to ensure that the voice of young people is present at all stages of care and support. Increasingly youth participation in mental health settings has become widely valued and respected as a right (Monson \& Thurley, 2011) with identified benefits for the individual and the organisation (Revans, 2009; Checkoway, 2011; Coates \& Howe, 2014). As such, young people should be consulted with and have opportunities to share their suggestions and feedback in all areas of mental health service provision (McGorry et al. 2007). Service's such as Jigsaw, ReachOut and St. Patrick's have embraced youth participation, but it is incumbent upon the spectrum of services to deliver on a human rights approach to youth mental health that puts youth participation at its core.

\section{Develop a systemic, integrated approach to service provision}

At present, there is an opportunity to advance leadership and vision within the Irish mental health service sector. However, there are numerous statutory and voluntary mental health services and organisations working across Ireland, and while acknowledging the invaluable support provided by many of these services, this work is too often reactive and un-coordinated. Internationally it is accepted that we need a health care system that can rapidly engage young people and provide comprehensive, integrated treatments and support services across the spectrum of need (McGorry, 2007). For example, a tiered approach in Australia has been successful in addressing early intervention for common mental health problems, as well as attending to young people with complex presentations or more severe conditions who require a more intensive level of support and specialised care (McGorry et al. 2013). Whilst there have been some developments aimed at enhancing service provision (e.g. the introduction of standard operating procedure for Child and Adolescent Mental Health Services in 2015, funding for 100 assistant psychologist posts for youth mental health in 2017), joined up thinking is required in order to ensure such developments result in integrated service delivery. An initial first step could be the establishment of a leading authority for the youth mental health sector. Such an authority could ensure the adequate resourcing of the sector to create quality and responsive services (Coughlan \& Doyle, 2015). Practical actions such as a detailed audit of supports and services operating within the Irish mental health sector would be welcome. Such an audit would facilitate the identification of opportunities to configure services in a way that meets youth mental health need and is consistent across the country. Greater opportunities for collaboration 
and partnership amongst services are also desirable (Hughes et al. 2017) and would be a natural result of a more systemic approach to service provision.

\section{Create/provide a single access point}

Many mental health services in Ireland are overly arduous to access. GPs and emergency departments are currently acting as an access point into care, but this system is neither working efficiently nor effectively. Trust in the provider and cost of access to care is a key issue for young people (Gulliver et al. 2010). A single free, confidential access point is needed, which would provide rapid and appropriate signposting for routine, urgent and emergency referrals. This access point should operate 24 hours a day, 7 days a week, 365 days per year and cover the spectrum of mental health need, from mild to moderate to severe. As well as accepting referrals from health professionals and statutory services, the possibility of self-referral through this single point of access should be explored. Self-referral has been operating successfully in the Jigsaw service for several years and whilst we acknowledge potential challenges in implementation across the spectrum, selfreferral would greatly improve accessibility to services for young people.

\section{Revise/change the cut-off age for services}

Mental health services have traditionally tended to be allocated based on client age; with 18 years old generally cited as the cut-off point at which adult services assume responsibility from child and adolescent services. Coughlan \& Doyle (2015) propose that the use of age as a criterion for inclusion or exclusion has potentially resulted in many young people aged 16-18 years old being excluded from both child and adolescent and from adult mental health services solely on account of their age. Internationally there exists a strong case for a paradigm shift in mental health service provision, whereby services are informed by epidemiological evidence and organised on the basis of need (Coughlan \& Doyle, 2015). For example, Jigsaw has embraced this paradigm shift by offering a service to young people aged $12-25$ years thus providing a template to guide the reconfiguration of other services to cater more appropriately for the needs of young people.

\section{Invest in low-cost, high-scale online supports}

Although the international evidence for online mental health supports for young people is not yet conclusive, there is evidence that such supports can have a significant positive impact on adolescent health and wellbeing (Clarke et al. 2015). Initial studies indicate that investment in quality-assured, low-cost, high-scale online resources can promote positive mental health, increase youth mental health literacy and ensure consistent signposting of supports (Clarke et al. 2015), as well as reflect the help-seeking preferences and behaviours of young people (Dooley \& Fitzgerald, 2012; Karwig et al. 2015). There is also promising evidence that computerised cognitive behavioural therapy interventions can aid in the management of adolescent and emerging adult's anxiety and depression. Ireland is well positioned to take advantage of the online landscape with organisations such as ReachOut already providing high-quality online information and signposting. Given the emerging evidence, coupled with the high level of technology usage and availability amongst Irish adolescents, it makes sense that the development of online supports should be a priority.

\section{Develop a coordinated approach to education settings}

Outside of service provision, and with primary prevention in mind, education settings, in particular schools, have long been identified as having a vital role to play in the promotion of youth mental health (Franklin et al. 2012). While national guidelines related to well-being in primary and post-primary schools do exist, there is a sense that they do not go far enough and that much of the work in terms of mental health awareness and education is being conducted by community and nongovernmental organisations. To ensure the safety and responsible education of students, this work needs to be coordinated and evaluated. This links back to our point on a systemic approach to youth mental health provision, whereby one leading authority could be tasked with overseeing the sector. It also requires collaboration between organisations who provide content in schools to ensure consistency. For example, mental health training for teachers (both pre-service and in-service) and school staff should be mainstreamed to ensure quality and consistency. Cognisant of the fact that universal wellbeing programmes may not meet sufficient need within schools, targeted and evidence-based prevention programmes should also be introduced to support optimal mental health outcomes for young people (Weare \& Nind, 2011).

Similar issues, of inconsistency and lack of coordination and evidence-based supports, exist in the field of higher education and our considerations extend to this setting also (Hunt \& Eisenberg, 2010). Given that most mental disorders have the first onset by young adulthood (Kessler et al. 2005), and approximately 60\% of young adults attend post-secondary education in Ireland, higher education provides one of the best opportunities for the prevention, detection and treatment of early onset disorders. 


\section{Conclusion}

Best practice has been adopted in many areas of the youth mental health sector and several organisations such as Jigsaw, ReachOut and St. Patricks have been at the forefront of positively shaping the Irish youth mental health landscape. Much of this work has been supported and funded by the national HSE who have demonstrated a commitment to advancing youth mental health services in Ireland. However, issues of barriers into care as well as discontinuity of care and poor integration across the spectrum of services persist and require significant national engagement to tackle. International models such as Orygen in Australia and Adolescent/young adult Connections to Community-driven Early Strengths-based and Stigmafree services network in Canada provide useful case studies for overcoming challenges and advancing change in the Irish context. In addition, recent positive developments such as the launch of the National Youth Mental Health Taskforce Report 2017 (Department of Health, 2017) aligns well with direction outlined here and demonstrates that Ireland has the momentum and expertise needed to effect transformational change. What is not clear is the availability of resources required to achieve this change. Given the credible evidence that well-implemented programmes for young people can achieve significantly more benefits than costs (Zechmeister et al. 2008; Clayton \& Illback, 2013) investment now will reap the significant health and financial benefits into the future.

\section{Conflicts of Interest}

All authors have no conflicts of interest.

\section{Ethical Standards}

The authors assert that all procedures contributing to this work comply with the ethical standards of the relevant national and institutional committee on human experimentation with the Helsinki Declaration of 1975 , as revised in 2008.

\section{Financial Support}

This research received no specific grant from any funding agency, commercial or not-for-profit sectors.

\section{References}

Birchwood M, Singh SP (2013). Mental health services for young people: matching the service to the need. British Journal of Psychiatry 202 (Suppl. 54): s1-s2.

Bo M (2017). Hunting down an evidence base for adolescent mental health. The Lancet Psychiatry 4, p83.

Burns J, Birrell E (2014). Enhancing early engagement with mental health services by young people. Psychology Research and Behavior Management 7, 303-312.
Cannon M, Coughlan H, Clarke M, Harley M, Kelleher I (2013). The Mental Health of Young People in Ireland: a report of the Psychiatric Epidemiology Research across the Lifespan (PERL) Group. Royal College of Surgeons in Ireland: Dublin.

Checkoway B (2011). What is youth participation? Children and Youth Services Review 33, 340-345.

Clarke AM, Kuosmanen T, Barry MM (2015). A systematic review of online youth mental health promotion and prevention interventions. Journal of Youth and Adolescence 44, 90-113.

Clayton R, Illback R (2013). Economic Burden and Cost to Government of Youth Mental Ill-Health. Jigsaw, The National Centre for Youth Mental Health: Dublin.

Coates D, Howe D (2014). The importance and benefits of youth participation in mental health settings from the perspective of the headspace Gosford Youth Alliance in Australia. Children and Youth Services Review 46, 294-299.

Costello EJ, Copeland W, Angold A (2011). Trends in psychopathology across the adolescent years: what changes when children become adolescents, and when adolescents become adults? Journal of Child Psychology and Psychiatry 52, 1015-1025.

Coughlan H (2013). Paper for the Irish College of Psychiatry to launch the beginning of their chosen theme of Youth Mental Health in 2013. Department of Psychiatry, Royal College of Surgeons in Ireland on behalf of the ACAMH Special Interest Group on Youth Mental Health in Ireland.

Coughlan H, Doyle M (2015). Youth mental health in Ireland: a lot done, more to do? Irish Journal of Psychological Medicine $32,5-8$.

Coughlan H, Tiedt L, Clarke M, Kelleher I, Tabish J, Molloy C, Harley M, Cannon M (2014). Prevalence of DSM-IV mental disorders, deliberate self-harm and suicidal ideation in early adolescence: an Irish populationbased study. Journal of Adolescence 37, 1-9.

Dell'Osso B, Glick ID, Baldwin DS, Altamura AC (2013). Can long-term outcomes be improved by shortening the duration of untreated illness in psychiatric disorders? A conceptual framework. Psychopathology 46, 14-21.

Department of Health (2017). National youth mental health task force report 2017. Stationary Office, Dublin (http:// health.gov.ie/wp-content/uploads/2017/12/YMHTF-FinalReport.pdf). Accessed 7 December 2017.

Dooley B, Fitzgerald A (2012). My World Survey: national study of youth mental health. The National Centre for Youth Mental Health, University College Dublin and Headstrong: Dublin.

Franklin CG, Kim JS, Ryan TN, Kelly MS, Montgomery KL (2012). Teacher involvement in school mental health interventions: a systematic review. Children and Youth Services Review 34, 973-982.

Gulliver A, Christensen H, Griffiths KM (2010). Perceived barriers and facilitators to mental health help-seeking in young people: a systematic review. BMC Psychiatry 10, 113.

Hughes F, Hebel L, Badcock P, Parker AG (2017). Ten guiding principles for youth mental health services. Early Intervention in Psychiatry 11, 1-7. 
Hunt J, Eisenberg D (2010). Mental health problems and help-seeking behavior among college students. Journal of Adolescent Health 46, 3-10.

International Declaration on Youth Mental Health (IAYMH) (2011). A shared vision, principles and action plan for mental health service provision for young people aged 12-25 years. (http://www.iaymh.org/f.ashx/8909_IntDeclaration-YMH_print.pdf). Accessed 7 December 2017.

Karwig G, Chambers D, Murphy F (2015). Reaching out in college: help-seeking at third level in Ireland. ReachOut Ireland.

Kessler RC, Angermeyer M, Anthony JC, De Graaf RON, Demyttenaere K, Gasquet I, De Girolamo G, Gluzman S, Gureje OYE, Haro JM, Kawakami N (2007). Lifetime prevalence and age-of-onset distributions of mental disorders in the World Health Organization's World Mental Health Survey Initiative. World Psychiatry 6, 168-176.

Kessler RC, Berglund P, Demler O, Jin R, Merikangas KR, Walters EE (2005). Lifetime prevalence and age-of-onset distributions of DSM-IV disorders in the National Comorbidity Survey Replication. Archives of General Psychiatry 62, 593-602.

Kohn R, Saxena S, Levav I, Saraceno B (2004). The treatment gap in mental health care. Bulletin of the World health Organization 82, 858-866.

Malla A, Iyer S, McGorry P, Cannon M, Coughlan H, Singh S, Jones P, Joober R (2016). From early intervention in psychosis to youth mental health reform: a review of the evolution and transformation of mental health services for young people. Social Psychiatry and Psychiatric Epidemiology 51, 319-326.

McGorry P, Bates T, Birchwood M (2013). Designing youth mental health services for the 21st century: examples from Australia, Ireland and the UK. The British Journal of Psychiatry 202, 30-35.

McGorry P, Purcell R, Hickie I, Jorm A (2007). Investing in youth mental health is a best buy. Medical Journal of Australia 187, 5-7.

McGorry PD (2007). The specialist youth mental health model: strengthening the weakest link in the public mental health system. Medical Journal of Australia 187, S53-S56.
Mental Health Commission (2017). Continued admission of children to adult mental health units 'totally unacceptable' says Mental Health Commission. Murray, on behalf of the Mental Health Commission: Dublin (http:/ / www. mhcirl.ie/File/PR_AR2017.pdf). Accessed 7 December 2017.

Mental Health Reform (2015). A Vision for Change Nine Years On: A Coalition Analysis of Progress. Mental Health Reform: Dublin.

Monson K, Thurley M (2011). Consumer participation in a youth mental health service. Early Intervention in Psychiatry 5, 381-388.

O'Reilly A, Illback R, Peiper N, O'Keeffe L, Clayton R (2015). Youth engagement with an emerging Irish mental health early intervention programme (Jigsaw): participant characteristics and implications for service delivery. Journal of Mental Health 24, 283-288.

Patton GC, Sawyer SM, Santelli JS, Ross DA, Afifi R, Allen NB, Arora M, Azzopardi P, Baldwin W, Bonell C, Kakuma R, Kennedy E, Mahon J, McGovern T, Mokdad AH, Patel V, Petroni S, Reavley N, Taiwo K, Waldfogel J, Wickremarathne D, Barroso C, Bhutta Z, Fatusi AO, Mattoo A, Diers J, Fang J, Ferguson J, Ssewamala F, Viner RM (2016). Our future: a Lancet commission on adolescent health and wellbeing. The Lancet 387, 2423-2478.

Revans L (2009). The participation of young people in developing social care. Community Care 28, 24-26.

United Nations General Assembly (2010). Mental Health and Human Rights (https:/ /documents-dds-ny.un.org/doc/ UNDOC/LTD/G16/135/78/PDF/G1613578.pdf? OpenElement). Accessed 7 December 2017.

Weare K, Nind M (2011). Mental health promotion and problem prevention in schools: what does the evidence say? Health Promotion International 26 (Suppl. 1): p29-p69.

Zechmeister I, Kilian R, McDaid D (2008). Is it worth investing in mental health promotion and prevention of mental illness? A systematic review of the evidence from economic evaluations. BMC Public Health 8, 20. 